\author{
ABSTRACT \\ THE ORGANIZATION OF FAMILY INTERACTIONS: \\ MINIMIZING TRANSACTION COSTS AND STRATEGIC BEHAVIOR \\ Donald Wittman \\ Department of Economics \\ University of California \\ Santa Cruz \\ wittman@ucsc.edu
}

The optimal organization of the family requires that relations are structured so that non-cooperative game playing is minimized and transaction costs are reduced. I show that therapeutic advice for behavior within the family is to create a functioning property rights system. Punishment is shown to be inferior to setting limits because the first encourages strategic game playing. I show why there is conflict between parent and their child even when the parent maximizes the child's expected discounted utility. In addition, I provide a model of the intergenerational transfer of behavior.

Keywords: internal organization of the family, transaction cost, psychology,

JEL classification: A12, D19, D74 


\title{
THE ORGANIZATION OF FAMILY INTERACTIONS: MINIMIZING TRANSACTION COSTS AND STRATEGIC BEHAVIOR
}

\author{
Donald Wittman \\ Department of Economics \\ University of California \\ Santa Cruz, CA 95064
}

August 12, 2004

In this article, I suggest that the advice (informal rules) provided by clinical psychologists for allocating and enforcing entitlements within families reflects sound economic judgement.

Economics and clinical psychology appear to be as far apart as is possible for two fields concerned with human behavior. Unlike the imperialistic encroachment of economic theory into law and politics and the symbiotic relationship between evolutionary biology and game theory, the intellectual intersection between economics and clinical psychology has been non-existent. Part of the explanation is methodological. In contrast to economics, books providing psychological advice have no theorems and few statistics. Even their fellow psychologists in cognitive and social psychology criticize the clinical approach for being non-scientific and non-experimental. And above all, clinical psychology appears to deal with "irrational" behavior of individuals. Hence, it should not be at all surprising that economics and clinical psychology have had little overlap. Despite the apparent gulf between these two fields, I will show that, in practice, the advice given by marriage and family counselors regarding behavior within the family is consistent with economic thinking and in some ways is more advanced. Ultimately, this is a more satisfying relationship between the two disciplines -- one theory of human psychology is better than two theories. If economists correctly believe that people are rational, then the help that rational people get from their psychologists and from popular psychology books should be consistent with rationality, especially so since patients can apply the advice and see whether it works in practice.

In the following pages, I show that clinical psychologists who employ codependency theory use the same conceptual apparatus as economists: rationality, choice, property rights, and fixity of preferences (or emotions). I argue that the therapeutic mode is to enable the patient to be the prototypical economic man. After the basic conceptual apparatus is presented, the ideas are developed more fully within the context of child rearing and the optimal organization of family responsibilities. I show that books on child psychology give parents good advice on how to reduce 
strategic game playing by their children and on how to organize family relations so that externalities are minimized. I then consider parental utility functions. Next, I discuss the intergenerational transmission of behavior. I finish with some thoughts about the future of this enterprise.

The approach to family structure discussed here is different from the evolutionary biological approach. While not denying the value of this approach, not all human wisdom is hard-wired, genetically programmed as preferences, or passed down culturally from parent to child so that only optimal family organizational structures have survived. Just as some people seek advice concerning the appropriate foods to eat to maximize health and longevity rather than relying solely on their hunger, and others get advice on how to diversify their portfolio rather than relying on their native intuition or traditional patterns of investment in their families, many parents seek wisdom on child rearing from those who specialize in family relations. ${ }^{1}$

The method of empirical validation used in this article is analogous to the methods used in the economic analysis of law. Scholars in law and economics typically use appellate court decisions, corporate charters, and the like as their source of empirical evidence. However, there are few, if any, legal documents regarding the internal organization of the family. Therefore, as a substitute for appellate court decisions, I will use statements from best selling books, such as Children: The Challenge by Dreikurs and Solz (1986) and Facing Codependence by Mellody, Miller and Miller (1989) as empirical confirmation of the theory presented here. ${ }^{2}$ Although the terminology of codependency theory is most prevalent among marriage and family counselors, the praxis of psychiatry often employs similar methods. Thus, while I focus on child-rearing guidebooks and codependence theory in particular, rather than clinical psychology and psychotherapeutic techniques in general, the underlying approach has wider currency than just those employing the particular codependence terminology.

\footnotetext{
1 People may need different skills in advanced industrial societies from those skills needed in hunter-gatherer or even agrarian societies, and therefore child raising may require different skills, as well.

2 Reference will also be made to Bradshaw (1988) when discussing codependence in general, to Satir (1983) when discussing family systems, Dinkmeyer and McKay (1989) when discussing child rearing, and to Miller (1981) when discussing the creation of personality.
} 


\section{A. CODEPENDENCE THEORY}

The general theory of dysfunctional relationships and how to change them can be found in popular books on codependence. In addition to the aforementioned book by Mellody, Miller and Miller (1989), Codependent No More by Beattie (1989), and The Family by John Bradshaw (1988) have all been best sellers. ${ }^{3}$ Much of codependence theory resonates with Coase's analysis of torts. There are two inputs into the production of damage. But codependence theory carries the idea of symmetry much further and, to a greater degree than even economic theory, leaves little room for mistakes. Furthermore, the theory provides an overlapping generations model of distortionary behavior.

\section{BOUNDARIES}

Boundary systems are invisible and symbolic "fences" that have three purposes: (1) to keep people from coming into our space and abusing us, (2) to keep us from going into the space of others and abusing them and (3) to give each of us a way to embody our sense of "who we are." (Mellody, et. al., p. 11)

Dysfunctional families have either enmeshed or walled boundaries within the system. Enmeshment is the term used to describe the violation of ego boundaries.... There is no possibility of intimacy in such a family because there are no whole people to relate to.... The other extreme of boundary problem is 'walled' boundaries. ... [T] he boundaries are so thick, there can be no interaction or intimacy. (Bradshaw, 1988, p. 70)

In codependency theory, the concept of boundaries and setting limits is fundamental. One sets different boundaries with different people at different times. A spouse can come up and hug you (usually), but a stranger cannot. In a kind of revealed preference theory, the boundaries that a person sets help to define the person's self. Each person in a relationship has to respect his/her own and the other person's boundaries (physical and emotional). Again I quote Mellody et; al. from page 11:

Our external boundary allows us to choose our distance from other people and enables us to give or refuse permission for them to touch us.... Our internal boundary protects our thinking, feeling and behavior and keeps them functional. When we are using our internal boundary, we can take responsibility for our thinking, feelings, and behavior and keep them separate from that of others, and stop blaming them for what we think, feel and do. Our internal boundary also allows us to stop taking responsibility for the thoughts, feelings and behaviors of others, allowing us to stop manipulating and controlling those around us.

\footnotetext{
3 Amazon.com lists over 300 books dealing with codependents or codependency.
} 
People with damaged or non-existent boundaries are labeled "co-dependent."

Codependents have dysfunctional relationships. They may have trouble protecting themselves and saying no; and/or they may violate other people's boundaries.

To give substance to these ideas, let us consider a married couple. Suppose that the wife is an abusive alcoholic. Alcoholism violates most people's core values. What should the non-alcoholic husband do in such situations? The therapist would not recommend that the husband try to stop his wife's drinking by being physically or emotionally abusive to her because that would violate her boundaries. Nor would the therapist recommend that the husband stay married to his wife if she continued to be an active alcoholic because then his core values or boundaries would be violated. ${ }^{4}$ Instead, the therapist would recommend that the husband set the following limit: if my wife continues to drink, I will get a divorce. Such a stand may appear to be unduly strong, but to not make it allows the alcoholic spouse to implicitly set the symmetric limit: If I cannot continue to drink, the marriage is finished.

Of course, most limit-setting need not be so drastic. For example, if the husband refuses to empty out his Kleenex tissues from his pants before he throws his pants into the dirty clothes pile and this results in the couple's clothes being covered with tissue residue, the wife can stop doing her husband's laundry rather than continue doing her husband's clothes and being bothered by it. This is setting limits on her behavior rather than trying to alter his behavior by violating his boundaries (for example, calling him names or purposely providing a burnt dinner).

Codependents are viewed as people who do not have the integrity to maintain their own values (boundaries). The values themselves are less often subject to scrutiny. An unhealthy person does not have a well functioning internalized boundary system. In the limit, certain psychotic states can be seen as a complete boundary breakdown so that the person cannot distinguish between I and thou. Patients with less serious psychological problems may have difficulty in distinguishing between their own wants and needs and others' (especially, their children's) wants and needs. The role of therapy is to enable the patient to devise a functioning boundary system.

\footnotetext{
${ }^{4}$ If divorce itself violated a core value, then the therapist might recommend another strategy such as living apart.
} 


\section{JOINT RESPONSIBILITY}

Codependency theory argues that people have choices and must take responsibility for being in harmful relationships. Our understanding can be enhanced by revisiting the abusive alcoholic, $\mathrm{X}$, and the husband, $\mathrm{Y}$.

The therapist first looks to see whether Y, has facilitated the outcome within the marriage. Perhaps, $\mathrm{Y}$ has made it easier for $\mathrm{X}$ to be cruel to $\mathrm{Y}$ by choosing to be self-sacrificing and not letting the costs of X's behavior fall on X. For example, Y may have tried to limit X's alcoholism (by yanking $\mathrm{X}$ out of bars) or Y may have reduced the impact of X's alcoholism (by helping X at work or by taking on extra burdens because $X$ cannot perform them while in an alcoholic stupor). These activities shift the cost of $\mathrm{X}^{\prime}$ s behavior onto Y. ${ }^{5}$ But even if $\mathrm{Y}$ has not facilitated the outcome within the marriage, $\mathrm{Y}$ has chosen the outcome by not divorcing $\mathrm{X} .{ }^{6}$ By choosing to remain married to $\mathrm{X}$, $\mathrm{Y}$ becomes responsible for the harm to $\mathrm{Y}$ that occurs within the marriage..

One role of the psychotherapist is to make the patient aware of his/her contribution to the output and to suggest alternative patterns of behavior that might change the outcome.

Modern therapy is very hesitant to accept the disease model of behavior. Saying someone is a paranoid or an alcoholic is blaming one side and allows both sides to avoid responsibility. It suggests that the person is sick or irrational and not in control and that the other person can do nothing to limit the impact on him or herself. Codependence theory believes that everyone has control over his/her behavior and that adults, especially, have choices. It allows neither party to absolve responsibility. $\mathrm{X}$ cannot blame $\mathrm{Y}$ for $\mathrm{X}$ 's drinking and $\mathrm{Y}$ cannot blame $\mathrm{X}$ for $\mathrm{Y}$ being a victim and staying in an abusive situation. $Y$ has chosen to be a victim.

\footnotetext{
5 In the words of transactional analysis, both parties have chosen to play their roles in this game. In the short-run, these activities may make sense from a cost-benefit analysis (the cost to $\mathrm{Y}$ if $\mathrm{X}$ is unemployed may be greater than the cost of yanking $\mathrm{X}$ out of bars). In the long-run, the cost may be too high because $\mathrm{X}$ will have no impetus to change, and $\mathrm{Y}$ will remain in an undesirable relationship.

6 Note the recurrent emphasis on individual choice as opposed to irrational drives or societal needs. The concept of "empowerment" is to make patients realize that they have choices.
} 


\section{B. AN ECONOMIC INTERPRETATION}

The leap from "boundaries" to "property rights" is a small one. Boundaries play the same role in personal relationships as property rights play in the economic sphere. Property rights prevent others from trespassing on our land, and property rights prevent us from trespassing on other people's land. The particular bundle of rights defines the nature of the property. When transaction costs are low and property rights are well-defined and enforced, productivity and efficiency is enhanced. Parallel results hold for boundaries.

Boundaries establish the core values of a person's sense of self - who the person is and wants to be. Essentially, creating boundaries is establishing one's basic preferences (for example, wanting children, having a career, being gregarious or wanting to be alone, etc.). Without knowing one's basic preferences, one cannot achieve much happiness because choices are random or imposed by others. ${ }^{7}$ Obviously, if one allows others to violate one's own boundaries, one is not going to be very happy in life; and less obvious, but also true, if one violates other's boundaries, then others will keep their distance and relationships will be difficult or impossible.

The invisible hand works in the following way. People should only be in relationships where their core values are not in conflict. A couple where one person wants a child and the other does not, where one person finds alcoholism inappropriate while the other drinks to excess, or where one person believes in altruism and reciprocity and the other does not, will find at least one person, most likely both people, unhappy. The alternative is being with someone else (psychologists argue that the relationship market is competitive - there is a better replacement) or being alone (it is believed that the person will be happier alone than in a situation where there core values are violated).

Thus, if each spouse protects his/her core values and prevents his/her own boundaries from being crossed, then the marriage will only last if neither spouse's core values are violated. This is the "first welfare theorem" of interpersonal relationships: each person protecting his/her fundamental interest will yield a Pareto optimal outcome.

Of course, not all values are core values. Where one goes to dinner or what clothes one wears are, for most people, not fundamental to their sense of self. Under such situations, one can

\footnotetext{
7 Economists tend to take for granted that individuals have well-defined preference sets. In contrast, psychologists do not assume this to be the case. Psychologists often help people in discovering and defining their basic preferences.
} 
accept the other's choice or negotiate. But even here the process should not violate one person or the other's boundaries.

One achieves one's objective by setting boundaries. You do not violate others' boundaries (property rights); you just make sure that they do not violate yours. The therapeutic method is to set limits rather than make war. The appropriate behavior within non-market small-number relations is to emulate voluntary transactions within a competitive market. If you do not like Daimler-Chrysler products, you do not firebomb their dealerships; you just do not buy their products. In interpersonal relations, you do not punish the other person (either physically or through guilt trips), and you do not try to control other person' s behavior (via jealousy, servitude or power). Instead, you set limits so that the other person does not do bad to you (the ultimate limit in a marriage, being divorce). In a nutshell -- even though there are only a small number of people involved, the normative model is the competitive solution rather than strategic game playing or authoritarian rule.

The therapeutic model tries to prevent other types of game playing, as well. In order to extract more from one's spouse, one might exaggerate one's boundaries and demands by hiding one's true preferences. But the model of appropriate behavior in a healthy relationship is intimacy where each side is honest with the other person and with themselves.

Turning to the concept of joint responsibility, codependency theory argues that both $\mathrm{X}$ (the alcoholic) and Y (the spouse) are responsible for the harm to Y. The psychologist does not allow Y to blame $\mathrm{X}$ because $\mathrm{Y}$ has chosen to remain a victim by staying married. And more obviously, the psychologist does not allow $\mathrm{X}$ to blame $\mathrm{Y}$ for $\mathrm{X}$ being an alcoholic. Both are inputs into the production of the harmful output that falls on Y. This jointness is greatly reminiscent of arguments made by Coase (1960), Brown (1973) and others regarding issues in the law -- both the polluter and the pollutee are responsible for the damage to the pollutee. It is misleading to say that the polluter alone causes damage to the pollutee, just as it would be misleading to say that labor but not capital causes the output of steel. Similarly, it would be misleading to say that $\mathrm{X}$ alone causes the damage to $\mathrm{Y}$ when $\mathrm{Y}$ chooses to remain married to $\mathrm{X}$.

But in deciding pollution cases, courts and the underlying economic analysis go beyond the observation of jointness. Courts are required to find one side liable. They undertake a cost-benefit calculation based on the average (reasonable) person and choose the efficient outcome. For example, if it is less expensive for the factory to install a smoke filter than for the laundry to hang its cloths indoors or move away, then the factory will be found at fault. 
In contrast, the therapist or marriage counselor does not act as a judge. Neither person is found liable or at fault; neither side is blamed. The marriage works for both parties or it doesn't the boundaries set by each person are either consistent (and a healthy relationship is possible) or they are not consistent (and a healthy relationship is not). The marriage counselor may help the spouses to understand their own boundaries, but it is up to each spouse to decide his or her boundaries and whether the marriage works.

We have seen that codependency theory has many similarities to economics. Like economics, it emphasizes that individuals have choices. Also, functional boundaries in codependency theory play the same positive role in personal relationships as property rights do in economic theory. However, the most interesting insights and parallels are found, not in terms of the overall approach, but rather in the specific suggestions for behavior. It is to these rules that we now turn.

\section{CHILD REARING}

In this section, I consider the internal organization of the family. I show how relationships can be structured so that externalities are minimized. I discuss how boundaries are implemented in child rearing via the use of a negligence rule. I comment on the child psychologist's concern with long-run incentive effects and show how the notion of joint outputs yields insight into the appropriate method of dealing with fights between siblings.

\section{THE NEGLIGENCE RULE AND MINIMIZATION OF TRANSACTION COSTS}

It is important to understand the difference between 'behavior and consequences' and 'Crime and Punishment.' The consequences should be, if possible, a reasonable follow-up related to what happened ... (Mellody, et. al., p. 140)

Let us say your son in junior high starts to forget his lunch every day. He calls you, his mother, and you take his lunch. To stop this behavior pattern, you sit down with him and say: "Look Charley, the normal consequences of not making arrangements for lunch is that you go hungry." Then when he forgets his lunch the next day and calls you again, you say. "I'm sorry. ... The normal consequences of your not taking lunch with you is for you to be hungry. I am not bringing your lunch." (Satir, 1972, quoted in Mellody, et. al., p. 140). ${ }^{8}$

\footnotetext{
8 This examples also appears in Dreikurs and Solz (1987, p. 76), but there the child is called Alfred.
} 
In this example, the recommended method is for the mother to set limits and let the consequences fall on her son. ${ }^{9}$ Using terminology from the economic analysis of law, the mother chooses a negligence rule. The victim (her son) is liable if the mother is not negligent. That is, if she has chosen the optimal (appropriate) level of care from her perspective, then the full cost of her son's behavior falls on him. ${ }^{10}$ As we will see, this is more efficient than the mother continuing to bring her son's lunch to school and then either hectoring him about it all the time or threatening to not let him watch television for a week.

Once the mother has done her job, she is out of the picture. The mother does not try to control Charley's behavior (or let him control her). She does not watch that he goes to school with his lunch; she does not use force by physically making him pick up his lunch; she does not threaten to harm him if he forgets his lunch; and she does not threaten to harm herself ("if you keep on forgetting, I will kill myself"). All these latter methods involve transaction costs. Neither parents nor psychologists had to hear from Coase to know that monitoring, threatening punishment and actual punishing are all costly. And they may not work -- hectoring by mom may bring her a sore throat, but Charley may just tune out.

More important, the method respects Charley's boundaries so that Charley learns what his boundaries are and how to make decisions and take responsibility in the absence of others. His motivation to remember bringing his lunch should not be based on whether his mother will be upset and will threaten to kill herself. Boundaries and private property exist because the effects on third parties are minimal, allowing optimal choices to be made while ignoring the concerns of others. If Charley's mother overly involves herself in making sure that Charley brings his lunch to school, then she is enmeshing her own issues onto something that is essentially Charley's issue. Of course, the well-meaning mother wants Charley to learn responsibility. But hectoring and punishing him is no way to make him responsible, because then his mother is responsible for the punishment, not Charley.

\footnotetext{
${ }^{9}$ Rousseau was an early proponent of the doctrine of natural and logical consequences. Sometimes the parent structures the logical consequences. For example, a parent cannot let a small child run into the street and face the natural consequences. However, the parent can warn the child that if he/she runs into the street, then for the rest of the day the child will have to stay inside where the child is in less danger. This is not a punishment, but a consequence of the parent protecting the child.

10 The costs of going without lunch are implicitly assumed to be minor. Charley will not face a serious medical emergency if he does not eat his lunch.
} 


\section{THE INDIFFERENCE PRINCIPLE}

The child psychologist's message is: (1) parents should change their own behavior rather than try to change their child's behavior; and (2) parents should not punish and control but instead provide choices. At first sight, the rationale for such recommendations seems contrary to economic intuition. After all, punishment is a type of incentive and the child always has the choice of whether to behave, thereby avoiding punishment. Furthermore, it is not immediately obvious why trying to change the other person's behavior might not be cost effective. But as I will now show, the psychologist's words are not mere sophistry. The underlying economic logic provides a strong theoretical explanation for their recommendations.

A good starting point for insight is to assume that a price system is feasible. Then the mother could charge Charley a price for her delivering lunch equal to the opportunity cost of her time plus driving expenses. In this way, the mother would be indifferent to Charley's choice. ${ }^{11}$ Charley would be free to choose whether he forgets his lunch, while the mother sets the appropriate baseline -- she makes his lunch but does not deliver it unless she receives adequate compensation. This system thus mirrors liability rules (which, in principle, try to make the victim whole and therefore indifferent to whether there is damage) more than Pigovian taxes or punishments (which try to change the criminal's behavior but leave the victim uncompensated and desiring greater deterrence).

Charley may not have enough money to bribe mom. But there may be close substitutes. Perhaps mother could have Charley dig in the garden for three hours, which might compensate her for the time to deliver lunch. This would not be a punishment, but treated as a charge for mother's time. Charley would then be given the option of whether his mother delivers lunch when he forgets it.

Unfortunately, a price system may not be feasible (the child's allowance may be too small), so the work of the child psychologist is much more difficult than that of the economist who only has to say that price should be set equal to opportunity cost. The psychologist needs to be much more creative in making a non-monetary system behave in the way a price (liability rule) system would. As is readily seen, the psychologist's recommendation in this case (don't deliver the lunch) closely emulates a price system in its effect. Once again, the mother is (almost) indifferent to

11 Economic equilibria create indifference at the margin. 
whether Charley takes his lunch since she does not deliver when he forgets. And once again Charley can choose to forget.

Now compare this to the punishment alternative. Mother delivers the lunch and then, as punishment, does not let him go out on the weekend. Having Charley stay at home on the weekend does not compensate mother. Therefore, mother is no longer indifferent to Charley's choices. If he forgets his lunch and she delivers it, she faces an uncompensated social cost. Charley's choice is imposing a negative externality on mother. Mother is strongly against this alternative from happening. Hence her interest is in controlling Charley's behavior, not in giving him a free choice. Almost by definition, a punishment system involves a dead-weight social cost. Preventing Charley from going out on the weekend does not compensate mother; so, she is choosing to be punished when she delivers the lunch. 12

The first theorem of welfare economics requires no externalities if there is to be economic efficiency. But a punishment system generates externalities. If the mother continues to bring Charley his lunch, then Charley is imposing an externality on his mother when he forgets, and she imposes an externality on him when he gets punished. Thus punishment is inherently a system riddled with externalities. ${ }^{13}$ Child psychologists help parents organize the household responsibilities so that such externalities and deadweight social losses are minimized.

Optimal domestic organization suggests that the mother structures the choice set available to Charley so that she is indifferent as possible to his choices. ${ }^{14}$ I will label this as the indifference principle. ${ }^{15}$ In a system where people are indifferent to other's choices, no externalities exist.

Psychologists are also very concerned with avoiding child-parent contests of power (or will) and win/lose situations. In such situations there is strategic game playing, domestic warfare and

\footnotetext{
12 The threat of punishment may not be credible if it requires additional costs such as monitoring the punishment. Note that a Pigovian tax (e.g., requiring Charley to donate money to a charity) is not an acceptable substitute for a liability rule, which compensate his mother. Under a Pigovian tax system, his mother is no longer indifferent and will, therefore, try to manipulate the outcome.

13 Even the criminal justice system is leery of using costly punishments. Fines are preferred to incarceration and incarceration is used mainly as a method to physically prevent further crime (the ability to commit crimes while in prison is greatly circumscribed) rather than as a punishment per se.

14 Thus this is not a maximin strategy but the creation of a dominant strategy.

15 The phrase "indifference principle" is my invention, not the psychologists.
} 
other behavior seeking to alter the utility of the other player. Each party is trying to change the other person's behavior rather than his/her own. All of these involve high social cost and the possibility of sub-optimal outcomes, and all of these arise because the mother is not indifferent. To illustrate, consider a solution that child psychologists dislike and where the indifference principle is violated - mother delivers forgotten lunches and Charley is punished by not being allowed to go out on the weekend. Mother is trying to control Charley, but Charley can avoid being controlled by his mother by controlling and punishing her -- making her deliver his lunch. This kind of warfare creates winners and losers and encourages strategic behavior. If Charley does not like losing the contest, he may purposely "forget" his lunch in order to impose a cost on his mother; although he is getting punished, Charley is victorious for having defied her. He can now prove that the threat of punishment does not work. Outcomes now depend on how each can manipulate the other person rather than the immediate and direct effect on their own utility functions. Each side is attempting to establish a reputation for toughness by imposing negative externalities on the other even though there is a cost to oneself. ${ }^{16}$ And once there is war, escalation is always possible.

Compare this to the case where Charley's mother does not bring the forgotten lunch. Since his mother is indifferent between both alternatives (Charley remembering and forgetting), Charley cannot make his choice to affect his mother's welfare or influence her behavior. Therefore he cannot engage in strategic behavior. Mother and child are not in a win/lose situation or in a situation which is a test of power; so Charley will make the decision based on his own wants and needs not on others'. Because she is indifferent, Charley's mother will not try to influence his behavior either. A similar analysis holds if Charley's mother is fully compensated for the cost her time if she does deliver the lunch.

Additional insight can be obtained by viewing the situation as a repeated game. Suppose that Charley's mother always delivers his lunch when he forgets to do so. Then the sequence can be modeled as a repeated multistage game. He chooses whether to bring his lunch; if he does not, his mother delivers and then chooses whether to punish him. In this repeated game the folk theorem may hold -- there are many equilibria, including the inefficient ones where each side tries to punish the other in order to obtain a more desirable equilibrium outcome. Compare this to the situation where the mother does not deliver the lunch. There are no bad equilibria, because at least in this

16 Anger may be used as a weapon by the parent to punish or control the child, but the child may control the parent by provoking the anger. 
simple characterization Charley cannot punish his mom by making her deliver. ${ }^{17}$ In a nutshell, the mother structures the game of family relationships so that there is no strategic manipulation.

The economic solution to Charley's forgetfulness is not solved by finding the optimal level of punishment when mother delivers Charley's lunch -- parents need not call on economist to derive the first order conditions. ${ }^{18}$ Instead, the solution is found by structuring the situation so that the mother is indifferent to Charley's choice. By withdrawing from the situation entirely, mother not only stops considering the optimal level of punishments and rewards, she stops engaging in other high transaction cost activity, including the need to negotiate with Charley on the issue.

Hence the psychologist creed: change your behavior instead of trying to change the other person's behavior. If mother does not like bringing lunch, she stops bringing lunch rather than trying to change Charley so that he will bring his own lunch instead. Of course, his behavior may change: once she stops bringing, he may stop forgetting. But even if he continues to forget, she does not try to change his behavior.

\section{THE CONCERN FOR LONG-RUN INCENTIVE EFFECTS}

Limits and pricing schedules need to be preset so that rent-seeking and other transaction costs are minimized. Consider the following classic example of the child throwing a temper tantrum in a supermarket (Nichols and Schwartz, 1991, p. 322):

The little girl asks her mother for a candy bar; the mother says, "No." The child begins crying and complaining, and the mother says, "If you think I'm going to buy you candy when you make such a fuss you have another thing coming, young lady!" But the child escalates her tantrum, getting louder and louder. Finally, the exasperated and embarrassed mother gives in, saying, "All right, if you quiet down first, I'll buy you some cookies."

The child is learning that violating property rights (boundaries) is a way of getting what she wants. Now it is true that, in the short-run, offering a cookie to a child is likely to stop the tantrum; but economists and psychologists have their eyes on the long-run implications. A more incentive compatible behavior by the mother is to set the rules ahead of time. For example, before entering the

\footnotetext{
17 Of course, the real world is never as simple as the simple characterizations in the child-rearing text. Charley may choose to scream at his mother for not delivering his lunch, thereby complicating the simple game tree. But the same idea holds -- mother sets limits instead of punishing.

18 The first order conditions must consider the supply of offenses when the punishment involves a deadweight loss.
} 
supermarket, the mother might say to the child that she cannot come with her next time if the child throws a tantrum. Not taking the child next time is not treated as a punishment for bad behavior this time, but rather as the natural desire of the mother not to want to take a child who will throw a tantrum. Once again, the emphasis is on restructuring the situation rather than on trying to change the child by punishing. Because the mother is basically indifferent between leaving the child home with her husband or taking the child shopping when the child behaves, the mother cannot be manipulated.

Why don't child psychology texts recommend slapping the child if she misbehaves? This is a kind of tit-for-tat and tit-for-tat is generally regarded as one of the more successful resolutions to repeated games. The answer is the same as before -- the parent does much better by restructuring the situation and playing a different game where strategic behavior by both sides is eliminated. If feasible, the child should be left at home. If leaving the child at home is not a viable option, then before entering the supermarket the mother might say one of the following: "If you behave, I will give you a cookie," "a point on your behavior chart," or nothing (depending on what the mother thinks is the appropriate reward even if there was no implied threat of a temper tantrum). In this way, transaction costs are reduced. The child will not throw a tantrum or engage in other forms of rent seeking in order to get a cookie.

Why does the psychologist recommend that the parent reward the child with a cookie for good behavior (a positive tit-for-tat) rather than slapping (punishing) the child for bad behavior? Isn't the difference between reward and punishment merely semantic -- not getting a cookie is a punishment for not behaving. But there is a difference -- a punishment such as slapping involves a deadweight loss and violates the child's boundaries (property rights). ${ }^{19}$ Not giving a cookie is withdrawing from the market and there is virtually no deadweight loss from giving a cookie. ${ }^{20}$

\section{SIBLING FIGHTING AND JOINT OUTPUTS}

In a fight it is difficult to establish who is guilty. It is not the result of the misbehavior of one child -- they all contribute equally to the disturbance, which is the result of their combined

\footnotetext{
19 "If a father physically abuses his son, for instance, the son's experience of the attack on his body tells him that his body is not worth being respected ... and that he has no right to be free from painful touches, and he has no right to control what happens to his body." (Mellody, et. al., p. 139) That is, the father has not respected the child's boundaries.

20 If the mother "docked" the child's allowance for misbehavior, there would not be a deadweight loss, either.
} 
effort. ... The children are ... coordinating their efforts whether for the welfare of the family or for the furtherance of its tensions and antagonisms. (Dreikurs and Solz, 1987, p. 261).

Many of the ideas presented in the earlier sections are embodied in how to handle fighting between siblings. The basic advice by child psychologists is to stay out of it. Fighting is a joint output. Putting the blame on one child because he did the hitting or because he is older and therefore should know better is a failure to recognize this jointness. If the parents protect the child that ends up crying, then children will use crying to get their way; that is, they will learn to provoke their older sibling and manipulate their parents, rather than learning to resolve problems. ${ }^{21}$ If the parents protect the abuser, then children will learn to abuse others' boundaries rather than find shared solutions to problems. Furthermore, by interfering the parent may also be an unwitting input. Perhaps both children have motives to get the parent's attention. One child may want to get the other in trouble; the other child may want to get attention, even if it is negative attention. But even if the children do not want to fight, constant intervention by parents shifts the cost of dispute resolution onto the parents and prevents the siblings from learning how to resolve the disagreement by themselves. While the parents might want to give guidance on how to resolve conflicts, it is not up to them to settle disputes or assign blame, unless both siblings ask. "One can, and should, have a friendly discussion about fights, without the least hint of finger pointing ... and work out with the children the way and means of settling difficulties. However, this cannot be done while the fight is taking place." (Dreikurs and Solz, 1987, p. 214)

But what if an older child truly terrorizes a younger one? Once again, the solution for the parents is to structure the situation so that strategic behavior by the children is minimized. For example, the parents may have rules that the children are in a room at different times. Indeed, whenever feasible, sending children back to their individual rooms is a good strategy. First, withdrawal from conflict (not violating the other's boundaries) is a good lesson for the children to learn. Furthermore, it sets a relatively neutral and non-manipulatable (by the other child) status quo point from which each child can bargain with the other to obtain a positive outcome (for example, playing together in the living room). By sending the children back to their rooms, the parents do

21 "If the parents blame the older child or stand up for the seemingly 'abused' one, then the parents reinforce the 'victims' feelings of inferiority and teach the victim how to use deficiency and weakness to gain special consideration, thus augmenting the very predicament the parents want to eliminate." (Dreikurs and Solz, 1987, p. 213). 
not enter the conflict or take part in the quarreling. They are not judges; they are just setting limits and minimizing strategic game playing by their children. ${ }^{22}$

\section{UTILITY FUNCTIONS}

Therapists believe that most knowledge is gained through the discipline of the market (the doctrine of logical consequences). For example, we let children take a chance of falling down on their skis; otherwise they do not learn to ski. Even if a child suffers from a choice, it may be the only way that the child can learn.

Because they do not have the cognitive skills or emotional maturity, children may not consider consequences in the distant future. This can be viewed as excessive risk-taking and/or excessive discounting of the future. We will concentrate on the latter view.

Parents are concerned with their children's welfare. Therefore, they try to structure the child's choices so that the consequences are appropriate and within the child's grasp. They may say to their 11-year old daughter that she can have candy only if she brushes her teeth afterwards. They do not say to their child that she can do whatever she wants to about brushing her teeth since she is the one who will face the dental consequences in 5 or 10 years if she doesn't. ${ }^{23}$

\section{ALTRUISM}

The relationship between an altruistic parent and his/her children can be characterized by the following pair of utility functions:

Altruistic parent's utility $=\alpha \sum_{t=0}^{n}\left[\delta_{P}\right]^{t} U_{P}^{t}+(1-\alpha)\left(\sum_{t=0}^{n}\left[\delta_{P}\right]^{t} U_{A}^{t}+\sum_{t=0}^{n}\left[\delta_{P}\right] U_{B}^{t}\right)$

22 The operative word is "minimize" since it is impossible to eliminate all strategic game playing.

23 Nor, for reasons discussed earlier, do they continue to provide candy and then punish their daughter for not brushing her teeth after she eats it. Note that the parents withdraw from providing candy, rather than withdraw from being parents. In real life, the situation is often more complicated and requires a more complicated solution. Nevertheless, the same principle holds - the parents should not violate either their own or their children's boundaries. 
where there are two children, $\mathrm{A}$ and $\mathrm{B}$, with $0<\alpha, \delta_{\mathrm{P}}<1$.

$$
\text { Child A's utility }=\sum_{\mathrm{t}=0}^{\mathrm{n}}\left[\delta_{\mathrm{A}}\right]^{\mathrm{t}} \mathrm{U}_{\mathrm{A}}^{\mathrm{t}} \text {, where } \delta_{\mathrm{A}}<\delta_{\mathrm{P}} \cdot{ }^{24}
$$

Conflicts arise between altruistic parents and their children because their utility functions are not perfectly aligned and because their discount rates differ. Parents must allow their children to have minor harms, because learning is costly but necessary for a child's long-run happiness. So it would be a mistake for the parent to prevent all harms to the child. At the same time parents must protect their children from major harms that reduce a child's happiness in the long-run even though the child does not realize that the present desirable action may lead to a serious long-run harm (e.g., playing in the street). ${ }^{25}$

Learning is slow and requires lots of practice. Children learn by doing and emulating. They only learn to be responsible adults by taking on responsibility for their choices. Altruistic parents have their eyes on the long-run - they derive utility from their children maturing and becoming selfactualized and responsible adults. These parents value their children's unique creation of their own boundaries and their children's assumption of responsibility for respecting their own boundaries as well as the boundaries of others. In this way their children's long-run welfare is maximized.

24 The utility functions could be more complex. For example, the parent's utility function could encompass the spouse's utility, while the child's utility might put some small weight on the parent's utility. Conceptually, it is easiest to view the child's utility function as a given; this is likely to be the case for the fundamental components of personality (for example, no matter what the parents want or do, they are unlikely to change the child's sexual orientation). Of course, parents can alter the child's opportunity set and thereby affect the way their children gain utility. If we allow for the possibility that parents can actually alter their children's utility functions in the desired direction, then the parent al utility function would account for this reverberating affect. But this attempt to change the utility function should not be so strong that it becomes dysfunctional (see the next section).

25 Some people, even when they are adults, are not able to adequately integrate the long-run consequences of their actions (e.g., heroin addicts). This can be characterized as an excessively low $\delta$. If such adults are parents and they seek advice from a psychologist, the psychologists is likely to try and help the patient to establish a longer perspective, thereby increasing $\delta_{\mathrm{P}}$. 


\section{REDUCING EMOTIONAL EXTERNALITIES}

As noted already, parents provide structured choices that are appropriate for the child. Within the context of these structured guidelines, psychologists recommend that parents be emotionally uninvolved in their child's choices -- they should not care whether their child has candy and brushes her teeth afterward or does not have candy in the first place. ${ }^{26}$ In this way the parents follow the child psychologists' recommendation that parents minimize their emotional involvement in both the child's choices and the child's present utility. ${ }^{27}$ Otherwise, the indifference principle does not hold and problems associated with control and strategic game playing arise.

Advice like "set limits rather than punish" is relatively easy to follow; there may be little emotional attachment to doing things one way or the other. This advice is akin to advice on how to grow vegetables. The home gardener is mainly interested in results and has little attachment to the process. The parent is asking the best way to raise healthy children. But the advice to reduce emotional externalities may require the parent to reassess and change their own utility function. This type of advice may be harder for the parent to follow even if it is characterized as changing the method rather than changing the parent's ultimate objective or utility.

In the previous section, I presented an altruistic parent's utility function. But not all parents have this type of utility function. Instead, a parent may have a utility function that is unhealthy for the child. I will label this type of utility function as dysfunctional.

A dysfunctional parent's utility $=\sum_{\mathrm{t}=0}^{\mathrm{n}}\left[\delta_{\mathrm{P}}\right]^{\mathrm{t}} \mathrm{U}_{\mathrm{P}}^{\mathrm{t}}\left(\mathrm{x}_{\mathrm{p}}, \mathrm{x}_{\mathrm{A}}, \mathrm{x}_{\mathrm{B}}\right)$

where $\mathrm{x}_{\mathrm{i}}$ is choices made by the parent $(\mathrm{P})$ and children $(\mathrm{A}, \mathrm{B})$.

The dysfunctional parent's interest is not in the long-term happiness of the child, but rather in the direct long-run happiness of the parent. Such parental preferences are unhealthy for the child because the child does not experience the "unconditional love" that the child would have received if the parent had the altruistic parental utility function. The dysfunctional parent's preferences may

\footnotetext{
26 Parents come to the child psychologist for advice. Hence the word "should."

27 We have already argued that parents have their eye on the long-run, making them less interested in their child's present state than in the child's growth toward adulthood.
} 
not coincide with the child's long-run welfare. For example, the parent might get more pleasure from the adult child being an economics professor than a dancer, even though the child's long-run happiness is maximized by being a dancer. But even if the dysfunctional parent wanted the same thing (for the child to be a dancer), the child would not feel as valued as a person, leading to a sense of being less than whole. And because the parent has a dysfunctional utility function, the child is likely to grow up to have a dysfunctional utility function, as well. ${ }^{28}$

Child psychologists suggest a number of methods to reduce emotional externalities of the unhealthy parent:

(a) "Refuse to become overly concerned about what other people think" (Dinkmeyer and McKay, 1989, p. 80). One characteristic of codependents is that their utilities are too dependent on others. "[C]odependents have ... other-esteem ... [which] is based on ... the opinion and behavior of other people ... [for example], how well their children perform [and] how powerful and attractive their spouse is" (Mellody et. al., p. 9-10). "Many parents hesitate to allow children to accept the consequences of their behavior because they fear disapproval from their own parents or from parents-in-law, friends, neighbors or teachers. Intimidated parents can gain courage from the realization that children are independent beings who must learn to decide how they will behave and that the children's behavior does not necessarily reflect on the parents as persons.... Parents cannot possibly be responsible for all their child's behavior" (Dinkmeyer and McKay, 1989, p. 80-81). Using economic terminology, parents' utility functions should not depend on what other people think about their children.

b) "Recognize who owns the problem. Parents assume ownership of many problems which are actually their children's" (Dinkmeyer and McKay, 1989, p. 81). If the child is satisfying his own needs and his behavior is not interfering with the parents, there is no problem and the parents should not get emotionally involved with their child's choices. The child painting his bike is the child's problem; the child painting the living room is the parents' problem. That is, when it is their children's problem, the parents' utility functions should not be dependent on their children's choices. ${ }^{29}$

\footnotetext{
28 There is considerable behavioral overlap between the altruistic utility function and the dysfunctional utility function (e.g., both types of parents might want their child to be healthy). So it is not clear which might have an evolutionary advantage. Note that happiness is not the same as genetic success.

${ }^{29}$ Not all problems can be allocated to just one party. Problems are joint when consumption is joint (e.g., the child likes to listen to loud music that the parents prefer not to hear).
} 
(c) "Avoid pity. Parents should not "protect" their children from responsibilities because they feel sorry for them" (Dinkmeyer and McKay, 1989, p. 80). ${ }^{30}$ Pity is very dangerous. It may either foster weakness in the child or be used against the parent.

Children learn to use their emotions to achieve ... [their] goals. For example, consider the children who have discovered the power that exists in tears: they may use tears to get their own way or to be excused from facing reality. The use of tears may be a form of "water power." ... Parents tend to believe these [sensitive] children are weak and need protection. ... What these parents don't realize is that [such] children ... are far from weak or fragile. They are very powerful! They are using their feelings to force others to treat them as special. ... Once parents recognize how children can use emotions to manipulate adults, ... parents can get out of the vicious cycle by refraining from reacting when children try to use emotions to manipulate them. (Dinkmeyer and McKay, 1989, p. 21-22)

While parents should be empathetic, being too concerned with the child's immediate happiness rather than the child's long-run happiness means that the parent is not indifferent and therefore is subject to manipulation and other strategic game-playing behavior that would be muted if the parent were concerned with the long-run happiness of their child.

Thus we have the underlying explanation for the recommendations by child psychologists. If parents value choices which should be the child's issues, then parents will create incentives for the child to satisfy the parents' wants and needs rather than the child's own needs and, consequently, make the child feel less than whole. If the parents are too authoritarian, then the child does not learn about making choices. If the parents are too permissive and ignore their own wants and needs (that is, they violate their own boundaries), then the child will not learn how to deal with other people's boundaries. If parents are too sympathetic to their child's pain, then the child will not be able to learn from failure and mature; that is, the child will not learn to be responsible for his own choices. In sum, parents should structure the child's environment so that the children become functional adults who maximize utility in the context of property rights rather than adult children.

\section{E. OVERLAPPING GENERATIONS MODEL OF BEHAVIOR}

In economics, tastes are given -- de gustibus non est disputandem. In psychology, emotions are treated as given. "We cannot change our emotions. What we feel is what we feel" (Mellody, et.

\footnotetext{
30 "Pity is not the same as empathy. Because we love our children, we want to show them we empathize, that we understand their feelings. Empathy promotes strength, whereas pity promotes weakness"
}

(Dinkmeyer and McKay, 1989, p. 81). 
al., p. 104). A psychologist does not argue with emotions any more than an economist would argue with someone's utility function. Books on child rearing are devoted to the topic of acknowledging the child's emotions rather than arguing with them.

Despite these and other similarities with economics, psychology places greater emphasis on the parent's role in the development of the child. In so doing, it creates an overlapping generations model of behavior.

\section{THE INCENTIVE STRUCTURE}

... because [the child] is helpless, his own survival needs must be met within the framework of his parent's needs and expectations. If he is going to get what he needs, his asking must be tuned to what his parents are willing and able to give. (Satir, 1983, p. 25)

Psychology provides numerous theories of behavior, some of them inconsistent, but all of them give parents a primary role in the development of the child's behavior beyond the purely genetic components of personality.

Just as in ordinary economic markets, infants and children respond to incentives. But the incentive structure within the family is more high powered and the resulting effects on children are much more permanent than the effect of prices on consumer behavior. In economic markets, monetary incentives are truly marginal. Decisions at the corporate headquarters of Burger King are unlikely to make much of an impact on the average consumer's overall behavior. But the child relies on its parents for survival. "A newborn baby is completely dependent on his parents, and since their caring is essential for his existence, he does all he can to avoid losing them. From the very first day onward, he will muster all his resources to this end, like a small plant that turns toward the sun in order to survive." (Miller, 1981, p. 8) 31

\footnotetext{
31 Since the parent is the agent for the child who is the genetic and social carrier for future generations, there are biological controls that mitigate the agency costs of parenting. Clearly, the baby's emotional control over the parent (bonding) reduces the agency costs and explains why parents rather than firms are primarily responsible for the caring of babies.
} 


\section{BOUNDARY PROBLEMS}

Very small children have no boundaries, no internal way to protect themselves from abuse or to keep from being abusive toward others. Parents need to protect their children from being abused by others (especially by the parents themselves). The parents also need to respectfully confront the children's own abusive behavior. It is this protection and confrontation by the parents that eventually teaches the children to have healthy and firm but flexible boundaries by the time they reach adulthood. (Mellody, et. al., p. 13)

Parents teach children skills. If parents have difficulty experiencing appropriate levels of esteem, then their children do not receive appropriate levels. If parents have difficulty taking care of their adult needs and wants, then children are not taught to meet their needs. If parents have a poor boundary system, then their children develop poor boundaries. "Children develop whatever boundary system the parents have. If a parent is dysfunctional and doesn't have an adequately developed boundary system, the child develops no boundaries or damaged ones ..." (Mellody, et. al., p. 80). Children of alcoholics are not only more likely to be alcoholics themselves, but also more likely to marry alcoholics even if they themselves are teetotalers; sexually abused children are likely to be sexually abused adults. 32

In dysfunctional families, parents try to shape the child to their own needs and wants, rather than to the child's. ${ }^{33}$ Their own feelings of inadequacy are projected onto the child (both emotional boundaries are crossed). For example, the parents may make the child feel less than whole because the child fails to live up to the parents' expectations about the child's athletic or intellectual abilities.

In sum, if the parents do not respect the boundaries of the child, then the child does not develop appropriate boundaries. A failure in the creation of an internalized property rights system in the child leads to a dysfunctional adult. The person fails to respect his/her own boundaries, the boundaries of others, or to even establish a sense of boundaries in the first place.

\section{F. CONCLUDING REMARKS}

The analysis of the internal organization of the family may provide the intellectual foundation for the neo-classical economic theory of the household just as the internal analysis of

\footnotetext{
32 See Cermak (1986)

33 Over-indulging a child or not challenging a developmentally challenged (handicapped) child within the context of his/her handicap is also dysfunctional.
} 
the corporation does for the neoclassical economic theory of the firm. Neo-classical economics assumes that corporations maximize profits. But this only comes about because of (1) the market for corporate control (e.g., tender offers, competition by states for corporate charters, etc.) that aligns the interests of managers with stockholders; (2) the intelligent assignment of property rights to the managers and stockholders that maximizes joint welfare; and (3) the application of linear programming, finance theory, and the like that allows the corporation to achieve its goal of maximizing profits. In parallel, neo-classical economics assumes that the family unit maximizes joint welfare. This paper shows how parents foster a functional property rights system so that joint welfare can be maximized.

Now other economists have looked at the family, but their focus is very different. Some have modeled the family as a single decision-maker that maximizes total welfare while others have treated the spouses as bargaining for shares of the pie based on their threat points. Very little attention has been devoted to the internal structure of family relations (especially between parents and children) and how the conflicting interests are resolved. The major exception is the 'Rotten Kid Theorem' and its extensions. Becker $(1974,1976)$ shows that a selfish child will maximize family income if she has partially altruistic parents (that is, her parents' utility is a function of income available to each family member). If the child selfishly pursues a path that results in greater earned income for herself but less in total for the family, maximization of utility by the parents will result in their reallocating their money away from the child. Since there is less total family income, the child will have less income (earned and given) if the child pursues such a selfish strategy. This is a clever solution to the puzzle of making selfish children act so that the total welfare of the family is maximized. It is also an example of the type of behavior recommended in this paper. The parents are neither punishing nor acting strategically, rather they are providing the scheduled distribution of income for each level of total family income. But no parent would say that this is all that is needed to make children behave and become responsible adults. Extensions of the rotten kid theorem consider the role of inheritance. Selfish children can be kept in line by a threat of not leaving them an inheritance if they misbehave. But their results are totally useless as a guide to dealing with most family matters. No child psychologist will recommend such a strategy. The present discounted value of an inheritance for a child of three is just too small; and once the child has chosen to be rotten, the threat is no longer effective. Hence, even the rotten kid theorem is only very distantly related to the issues raised here, and there is a need for a more detailed economic analysis of the organization of family relations. This paper is a step in that direction. 
Western economists have given advice to the former Communist countries on how to set up a system of private property and legal rules to replace the dysfunctional Communist systems. In the United States, psychologists are providing similar advice to individuals on how to set up personal boundary systems to replace dysfunctional relationships. In this way, each individual is responsible for his/her own behavior and does not try to blame others for his/her own choices. At the same time, child psychologists are giving parents advice on how to structure child-child and parent-child relations so that manipulation and other forms of non-cooperative game playing are minimized.

The established boundaries between economics and child psychology have been broken. I have shown that these two fields have a common core of ideas and share a similar philosophical stance -- the ideal family is much like the ideal economic market. The two fields have not advanced equally in all areas however. For example, child psychology emphasizes structure while the neoclassical theory of the firm tends to emphasize incentives (punishments and rewards). Each has something to contribute to the other.

For example, economic theory generally treats Pigovian taxes and liability rules as close substitutes with Pigovian taxes having the upper hand because they are less likely to distort the incentives of the person being harmed. Here Pigovian taxes were shown to be inferior because they create incentives for game-playing by the victim. This might provide insight into when and why court imposed liability rules are used instead of legislatively imposed Pigovian taxes. The transmission of boundary systems across generations is another area where economics might make gain from the insights of codependence theory. Economics does not have its own model of transmission and has had to borrow the genetic transmission model from evolutionary biology. But not all behavior is genetically transmitted. The cross-generation transmission of boundary systems could be viewed as a type of meme and might serve as a basis for economic models. 


\section{REFERENCES}

Beattie, Melody, Codependent No More, Harper and Row, New York, 1987.

Becker, Gary S. “A theory of social interactions,” Journal of Political Economy 1063-94 (1974).

Bradshaw, John, The Family, Heath Communications, Deerfield Beach, Florida, 1988.

Brown, John P. “Toward and Economic Theory of Liability, 2 Journal of Legal Studies 323-349 (1973).

Cermak, T. L., Diagnosing and Treating Codependence: A Guide for Professionals Who Work with Chemical Dependents, their Spouses, and Children, Johnson Institute, Minneapolis, 1986.

Coase, Ronald, "The Problem of Social Cost," 3 Journal of Law and Economics 1-44 (1960).

Dinkmeyer, Don and Gary McKay, The Parents Handbook, American Guidance Service, Circle Pines, MN, 1989.

Dreikurs, Rudolph, and V. Solz, Children: The Challenge, E. P. Dutton, New York, 1987.

Mellody, Pia, A. W. Miller and J. K. Miller, Facing Codependence, Harper and Row, New York, 1989.

Miller, Alice, The Drama of the Gifted Child, Basic Books, New York, 1981.

Nichols, Michael P. and Richard C. Schwartz, Family Therapy Concepts and Methods, Allyn and Bacon, Boston, 1991.

Satir, Virginia, Conjoint Family Therapy, Science and Behavior, Palo Alto, 1983.

Whitfield, Charles, Healing the Child Within, Heath Communications, Pompano Beach, 1987.

Whitfield, Charles, Codependence, Heath Communications, Deerfield Beach, Florida, 1992. 